\title{
Factors influencing career paths in Infectious Disease and/or HIV pharmacy: An exploratory study of pharmacy school graduates
}

\author{
Lindsey M. Childs-Kean ${ }^{1}$ (D), Sita Bhatt ${ }^{2}$, Eric F. Egelund ${ }^{1}$ (D) \\ ${ }^{1}$ Department of Pharmacotherapy and Translational Research, University of Florida College of Pharmacy, United States \\ ${ }^{2}$ University of Florida College of Pharmacy, United States
}

\section{Keywords \\ Careers \\ Elective \\ HIV}

Pharmacy specialities

\section{Correspondence}

Lindsey M. Childs-Kean

Department of Pharmacotherapy and

Translational Research

University of Florida College of Pharmacy

United States

Ichilds-kean@cop.ufl.edu

\begin{abstract}
Objective: This study aimed to determine what impact an elective course in HIV had on pursuing a speciality in Infectious Disease (ID) and/or Human Immunodeficiency Virus (HIV) pharmacy. Methods: Graduates enrolled in an HIV elective in three subsequent years were recruited. A cross-sectional study assessed what career path participants chose post-graduation, what impact the elective had on their career path, and if they obtained the AAHIVE/AAHIVP credential using this elective to fulfill the credential's educational requirement. Results: Three hundred and twenty-five emails were sent to graduates. Sixty-eight $(20.9 \%)$ participants responded. Ten of the respondents $(14.7 \%)$ considered themselves to be practising in ID pharmacy and/or HIV pharmacy. Of these ten respondents, four indicated that taking the HIV elective made them more likely to become an ID or HIV pharmacy specialist; seven of those respondents became, or are planning to become, an AAHIVE/AAHIVP-credentialed pharmacist. Conclusion: Taking an HIV elective may influence post-graduation career choices in this small cohort.
\end{abstract}

\section{Introduction}

Following completion of a Doctor of Pharmacy (Pharm.D.) programme, pharmacy graduates are free to choose from a myriad of career paths. The graduate can choose to seek employment in a wide range of settings or pursue additional training, including residency, fellowship, or postgraduate studies (e.g. Ph.D., MBA). Many factors contribute to the decision in pursuing a specific speciality or career path, including but not limited to pursuit of an appropriate work-life balance, interest in the specific discipline, gender, and available role models (Lent et al., 2009; Cordina et al., 2012; Yoon et al., 2018; Levaillant et al., 2020). Specifically related to Infectious Diseases (ID) and/or Human Immunodeficiency Virus (HIV) pharmacy practice, many graduates choose to pursue residency and/or fellowship training in order to gain clinical and research skills prior to starting full-time practice. However, the factors impacting the decision to track towards ID and/or HIV pharmacy practice are currently unknown. Therefore, the primary objective of this pilot study was to determine what factors influenced graduates' decisions to pursue their chosen career paths and to what extent, if any, an elective specialising in HIV management had in influencing those decisions. If such an elective course played a role in related career decisions, members of the Academy may decide to offer more or similar clinically-focused elective courses.

Spanning eight weeks in the final semester of the Pharm.D. curriculum, the two credit HIV elective built on the HIV content covered in the required curriculum. The elective course was designed for students to complete lectures and readings prior to coming to class, with the in-class session focused on case discussions on 
the week's topic. Topics included multiple patient populations who have acquired or have been exposed to HIV, which were not covered in the required curriculum, including pregnant persons, children, persons living with HIV with treatment resistance, and pre- and post-exposure prophylaxis. There were six topic sections plus midterm and final exams in the elective. The course was co-coordinated by two fulltime faculty members who delivered the majority of the lectures and facilitated the in-class sessions on two of the four campuses. The in-class sessions on the other two campuses were facilitated by local ID or HIV speciality pharmacists. Any Pharm.D. student in their final semester was eligible to enrol in the HIV elective course; there was no enrollment cap.

A secondary objective of this study was to determine whether students pursued credentialing in HIV following graduation. The American Academy of HIV medicine (AAHIVM) has developed a national credentialing programme (HIV Specialist) for health care professionals (e.g. physicians, nurse practitioners, physician assistants, pharmacists) who care for persons living with HIV (AAHIVM, 2021). The aim of the AAHIVM is to improve the quality of HIV care, broadening patient access to care, and expanding the number of HIV-specialised health care professionals. In 2016, the author's elective course was approved by the AAHIVM to count as a substitute for the $\mathbf{3 0}$ hours of HIV-related continuing education needed to qualify for the credentialing exam. This approval was sought to remove a barrier that can prevent pharmacists from becoming HIV-credentialed (McLaughlin et al., 2018). Graduates interested in becoming credentialed had to also meet state licensure requirements for pharmacists, participate in direct and ongoing involvement in the care of at least 20 persons living with HIV within the 24 months preceding the date of application (e.g. direct clinical services, consultation or case review in a hospital, inpatient or outpatient clinic, or retail environment), complete the credentialing application, and pass the examination (AAHIVM, 2021).

\section{Methods}

All graduates enrolled in the "HIV: Challenges and Treatments" elective at a large, multi-campus Pharm.D. programme at a public university in the years 2015, 2016, and 2017 were invited to participate in this study. Potential participants were identified through course rosters, and their postgraduate email addresses were obtained from the College of Pharmacy alumni database. This subsection of graduates was chosen because it was hypothesised that students who chose to take an elective focusing on HIV would be more likely to pursue ID and/or HIV practice, and the authors were interested in the motivations for pursuing ID and/or HIV practice.

A cross-sectional study design was employed. A survey was sent to the identified graduates via email in November 2018. The survey was built in Qualtrics (Qualtrics International, Inc., Provo, UT and Seattle, WA) and was open for three weeks with two reminder emails sent to those who had not yet completed it.

The survey adapted questions from surveys used in other published pharmacy education studies looking at impact of electives on pharmacy student career interests (Overholser et al., 2010; Baia \& Strang, 2012; Bryles et al., 2012; Steinberg \& Cooper, 2015); additionally, the survey was reviewed by the College of Pharmacy's Director of Assessment for clarity prior to sending to participants. The survey contained three different sections: demographics, career pathway after graduation, and why or why not ID and/or HIV practice after graduation. In addition to demographics, all participants were asked about their current practice setting, any formal postgraduate training, board certifications, and whether their primary practice was in ID and/or HIV pharmacy. For those who indicated they were primarily practising in ID and/or HIV, additional questions were asked, including if they were completing or had completed an ID and/or HIV specialised residency, if they were or were planning to become an HIV credentialed pharmacist, if they completed any informal postgraduate ID training, what their primary reason for becoming an ID and/or HIV pharmacy specialist was, and whether or not taking the elective made them more or less likely to become an ID or HIV pharmacy specialist.

Individuals who completed the survey were eligible to receive a 10 dollar (USD) gift card. The results of the survey were analysed using descriptive statistics (count, percentage). The analysis was completed within Qualtrics. The study was deemed exempt by the institution's Institutional Review Board.

\section{Results}

Sixty-eight out of 325 graduates completed the survey (20.6\%). Demographic information can be found in Table I; the demographics of the participants are comparable to the overall student cohorts. Out of the 68 participants, almost half (45.6\%) identified as white or Caucasian. Over half of the respondents (55.9\%) identified as female, and almost all respondents (88.2\%) were in the age range of $26-30$. 
Table I: Demographic information of survey respondents

\begin{tabular}{ll}
\hline Question/Response & $\begin{array}{l}\text { Number (\%) } \\
\text { (n=68) }\end{array}$ \\
\hline Age range (years) & $5(7.4 \%)$ \\
$20-25$ & $60(88.2 \%)$ \\
$26-30$ & $3(4.4 \%)$ \\
$31-39$ & \\
\hline Gender & $38(55.9 \%)$ \\
Female & $28(41.2 \%)$ \\
Male & $2(2.9 \%)$ \\
Prefer not to respond & \\
\hline Ethnicity & $31(45.6 \%)$ \\
White or Caucasian & $19(27.9 \%)$ \\
Asian/Pacific Islander & $11(16.2 \%)$ \\
Hispanic or Latino & $2(2.9 \%)$ \\
Black or African-American & $5(7.4 \%)$ \\
Other & \\
\hline
\end{tabular}

Table II provides the response information for the questions asked to all respondents. The majority of participants responded that they currently practised in a hospital setting $(58.8 \%)$ and had completed or were currently completing a PGY1 residency (51.5\%). Some of the respondents' practice settings other than hospital, community, or clinic were medication therapy management, managed care, nuclear, and academia. Almost half had achieved board certification or planned to in the next six months $(48.5 \%)$. The majority of respondents considered themselves to not be primarily practising in ID and/or HIV pharmacy (85.3\%). Almost half $(43.1 \%)$ of those not practising ID and/or HIV pharmacy indicated that they pursued the other area due to more interest in that speciality. Other reasons for not practising in ID and/or HIV pharmacy were lack of job opportunities in the ID/HIV speciality, the time needed in residency training, and inability to match for PGY1 and/or PGY2 residency.

Of the ten respondents who reported practising in ID and/or HIV pharmacy, five completed or were planning to complete an ID and/or HIV specialised residency, and seven had become or planned to become an HIV credentialed (AAHIVE/AAHIVP) pharmacist in the next six months (Table III). Seven participants responded that their primary reason for becoming an ID and/or HIV pharmacist was that the subject matter was of interest to them. Other reasons indicated were: wanting to give back to the community, focusing on ID management of patients on a medical/surgical floor of a hospital, and pharmacists being able to be seen as an expert in the field of ID/HIV. When asked whether the HIV elective course made them more or less likely to become an ID and/or HIV pharmacist, six respondents said their interest remained the same with the remaining four respondents stating that the elective made them more likely. When asked about the primary reason for taking the elective course, six responded that they were interested in learning more about HIV pharmacotherapy. Nine respondents said that they did not have any prior personal or professional experience with persons living with HIV.

Table II: Current practice and postgraduate training information of all survey respondents

\begin{tabular}{ll}
\hline Question/Response & Number (\%) (n=68) \\
\hline Current pharmacy practice setting & \\
Hospital & $40(58.8 \%)$ \\
Community & $15(22.1 \%)$ \\
Clinic & $4(5.9 \%)$ \\
Other & $9(13.2 \%)$
\end{tabular}

Formal postgraduate training completed or currently completing ${ }^{\dagger}$

$\begin{array}{ll}\text { PGY1 residency } & 35(51.5 \%) \\ \text { PGY2 residency } & 18(26.5 \%) \\ \text { Fellowship } & 2(2.9 \%) \\ \text { Other } & 3(4.4 \%) \\ \text { None } & 27(39.7 \%)\end{array}$

Current board certification or pursuing board certification

Yes $33(48.5 \%)$

No $\quad 35$ (51.5\%)

Primary practice in infectious diseases and/or HIV

Yes $10(14.7 \%)$

No $\quad 58(85.3 \%)$

${ }^{\dagger}$ Participants could choose more than one response.

PGY = Post-Graduate Year; HIV = Human Immunodeficiency Virus

Table III: Demographics and motivations of respondents practising in Infectious Diseases and/or HIV pharmacy

\begin{tabular}{lc}
\hline Question/Response & Number (\%) (n=10) \\
\hline PGY2 in ID and/or HIV completed or currently completing \\
Yes & $5(50 \%)$ \\
No & $5(50 \%)$ \\
\hline Currently or pursuing HIV pharmacist credentialing \\
Yes & $7(70 \%)$ \\
No & $3(30 \%)$ \\
\hline Motivation for ID/HIV practice & $7(70 \%)$ \\
The subject matter is of interest to me & $1(10 \%)$ \\
I want to give back to this community & $2(20 \%)$ \\
Other & \\
\hline Did the HIV elective make you more & \\
likely to become an ID/HIV specialist? & $4(40 \%)$ \\
More & $6(60 \%)$ \\
About the Same & 0 \\
Less & \\
\hline HIV = Human Immunodeficiency Virus; PGY = Post-Graduate Year \\
ID = Infectious Diseases
\end{tabular}




\section{Discussion}

In this exploratory study, approximately $15 \%$ of survey respondents who had taken an HIV elective during the final year of their Pharm.D. training indicated that they were currently practicing in either ID or HIV pharmacy. This relatively high percentage in one speciality is not surprising as it is likely that individuals who are more interested in ID-related topics and practice would elect to take a challenging course in HIV management. Interestingly, it appears that at least a few more respondents would have pursued ID and/or HIV practice, but they were unable to match for a residency position or perceived that there were no available jobs in ID/HIV. The competitiveness of both matching for a residency position and searching for a specialised pharmacist job has increased in recent years, and the ability for these factors to impact career paths should be explored in future research (ASHP, 2021). The primary driver of respondents' current area of practice seemed to be the interest in a particular practice setting/speciality area.

Moreover, all of those practicing in ID and/or HIV stated that the HIV elective either increased their likelihood of becoming an ID and/or HIV pharmacist or had no impact, with four (of ten) indicating that it increased the likelihood. Therefore, it appears that the HIV elective may have impacted at least some students' career paths. It is encouraging to see that seven of the graduates practicing in ID/HIV reported using (or planning to use) the elective course to satisfy the educational requirement for the HIV pharmacist credential, indicating that the authors successfully removed that barrier for credentialing for some pharmacists.

Understanding the impacts of elective courses on a pharmacist's career choices is an area of research that has relatively limited data. Most published studies in pharmacy education have asked current pharmacy students about the impact of a course or course series. For example, Baia and Strang (2012) reported that offering an elective about academic pharmacy resulted in $40 \%$ of students who took the course indicating that they were considering academia as a career. Other published studies have looked at electives in research, oncology, and residency training and seen similarly high numbers of students interested in the area of focus after the course (Overholser et al., 2010; Bryles et al., 2012; Steinberg \& Cooper, 2015).

This study assessed the retrospective impact of an elective course by targeting alumni instead of current students. Kelley and colleagues in 2019 reported employment trends for Pharm.D. graduates of ten research-intensive colleges of pharmacy for a five-year (2013-2017) period. They found a lower rate of graduates accepting a residency position than what the authors found in this study (35.4\% vs $51.5 \%)$. The higher percentage in this study could be due to residency-bound students being more interested in an elective with an advanced clinical focus compared to all graduates. Kelley and colleagues also found that a significant percentage of graduates had problems with finding a job and/or residency; this finding seemed to emerge in the data from this study as well. Their study found that the top five factors in satisfaction or dissatisfaction in postgraduate plans were practice setting, opportunity for professional growth, geographic preferences, opportunity for advancement, and family or personal circumstances. However, their study did not look at personal motivations for going into selected career paths as this exploratory study did.

One of the limitations of this study is the low survey response rate (about 20\%). However, garnering data from alumni is difficult, as seen in the American Association of Colleges of Pharmacy National Alumni Survey response rates from 2018-2020 (9-10.6\%) (American Association of Colleges of Pharmacy Alumni Survey, 2018; American Association of Colleges of Pharmacy Alumni Survey, 2019; American Association of Colleges of Pharmacy Alumni Survey, 2020). The authors suspect that their increased response rate could have been due to several factors. First is that the survey was distributed by well-known faculty, instead of someone from the college/school who may not be known. Second, there was the opportunity for a gift card with successful survey completion. Third, participants practicing in ID and/or HIV might have been more motivated to participate due to the objective of the study; this limitation may have artificially increased the proportion of respondents practicing in ID/HIV. Another limitation of the study is the ability to pursue the motivating factors for graduates more fully. This is an opportunity for future research, including potentially qualitative research. An additional limitation of the study is that the authors only surveyed graduates who took an HIV-specialised elective and not all graduates, and the results may be limited to pharmacists practicing in an ID/HIV speciality. A final limitation is that the authors did not ascertain if the graduates were practicing in specifically HIV practice or in ID more generally. These last two limitations present an opportunity for future research in areas of pharmacy practice.

\section{Conclusion}

A significant percentage of Pharm.D. graduates who took an elective course on HIV management reported practicing in ID and/or HIV pharmacy, and some of 
them indicated that the elective played a role in that career path decision. Further research is needed to determine what other factors motivate pharmacists to pursue different career paths within the pharmacy profession.

\section{Acknowledgements}

The authors would like to acknowledge Aaron Thomas, Ph.D. for providing them valuable assistance with designing the study survey in Qualtrics. They would also like to acknowledge Emily Huesgen, Pharm.D., BCACP, AAHIP for securing the approval from AAHIVM to have the elective course substitute for the required education hours to be an HIV credentialed pharmacist.

\section{Conflicts of Interest}

The authors have no conflicts of interest to disclose. This work was funded by an internal grant at the University of Florida College of Pharmacy. The authors have no additional financial interests to disclose.

\section{References}

American Association of Colleges of Pharmacy Alumni Survey (2020): 2020 National summary report. Available at: https://www.aacp.org/sites/default/files/2020-09/2020alumni-survey-national\%20summary\%20report.pdf

American Association of Colleges of Pharmacy Alumni Survey (2019): 2019 National summary report. Available at: https://www.aacp.org/sites/default/files/2019-09/2019alumni-survey-national\%20summary\%20report.pdf

American Association of Colleges of Pharmacy Alumni Survey (2018): 2018 National summary report. Available at: https://www.aacp.org/sites/default/files/2018-09/2018alumni-survey-national\%20summary\%20report_final.pdf

American Academy of HIV Medicine. (2021, May 13). Available at: http://aahivm.org

ASHP Match Statistics (2021). Available at: https://natmatch.com/ashprmp/stats.html

Baia, P., \& Strang, A. (2012). An elective course to promote academic pharmacy as a career. American journal of pharmaceutical education, 76(2), 30. https://doi.org/10.5688/ajpe76230

Bryles Phillips, B., Bourg, C. A., Guffey, W. J., \& Phillips, B. G. (2012). An elective course on postgraduate residency training. American journal of pharmaceutical education, 76(9), 174. https://doi.org/10.5688/ajpe769174

Cordina, M., Lauri, M. A., \& Lauri, J. (2012). Career paths and personality in pharmacy. International journal of clinical pharmacy, 34(6), 876-884. https://doi.org/10.1007/s11096012-9686-3

Kelley, K. A., Sweet, B. V., Janke, K. K., Plake, K. S., \& Yee, G. C. (2019). Employment Trends for Doctor of Pharmacy Graduates of Research-Intensive Institutions, 20132017. American journal of pharmaceutical education, 83(2), 6864. https://doi.org/10.5688/ajpe6864.

Lent R.W., Hackett G, Brown S.D. (2000). Contextual supports and barriers to career choice: a social cognitive analysis. Journal of Counseling Psychology, 47(1),36-49. https://doi.org/10.1037/0022-0167.47.1.36

Levaillant, M., Levaillant, L., Lerolle, N., Vallet, B., \& HamelBroza, J-F. Factors influencing medical students' choice of specialization: a gender based systematic review. (2020). EClinicalMedicine, 28:100589.

https://doi.org/10.1016/j.eclinm.2020.100589

McLaughlin, M., Gordon, L. A., Kleyn, T. J., Lamsen, M., \& Scott, J. (2018). Assessment of the benefits of and barriers to HIV pharmacist credentialing. Journal of the American Pharmacists Association : JAPhA, 58(2), 168-173.e3. https://doi.org/10.1016/j.japh.2017.12.010.

Overholser, B. R., Foster, D. R., Henry, J. R., Plake, K. S., \& Sowinski, K. M. (2010). The influence of an elective introductory clinical research course on pharmacy student interest in pursuing research-based careers. American journal of pharmaceutical education, 74(9), 165. https://doi.org/10.5688/aj7409165

Steinberg, M. \& Cooper, M. (2015). Impact of an oncology pharmacy elective course on guiding Doctor of Pharmacy students toward specializing in oncology pharmacy. Currents in Pharmacy Teaching and Learning. 7(5), 621-626. https://doi.org/10.1016/j.cptl.2015.06.001

Yoon, J.D., Ham, S.A., Reddy, S.T., \& Curlin, F.A. (2018). Role models' influence on specialty choice for residency training: a national longitudinal study. Journal of Graduate Medical Education, 10(2), 149-154. https://doi.org/10.4300/JGME-D17-00063.1 